\title{
Kan fusk på hjemmeeksamen forhindres?
}

\author{
G. Sindre, $N T N U$
}

\begin{abstract}
For hjemmeeksamen som skjer helt uten tilsyn, er fusk en storre bekymring enn for mange andre vurderingsformer. Plagiatsjekk kan være delvis effektivt for besvarelser som forventes å ha et sterkt individuelt preg, men i mindre grad for eksamensoppgaver med én eller noen få riktige løsninger, som ofte forekommer i grunnleggende MNT-fag. Erfaringer og anekdoter fra korona-våren 2020 tyder på et stort omfang av fusk. Forskningsspørsmålene for denne artikkelen er som følger: 1) Hvilke virkemidler fins for å redusere risikoen for fusk ved hjemmeeksamen, utover æreskoder og plagiatsjekk? 2) Hva er fordeler og ulemper med disse virkemidlene? Det sentrale bidraget $i$ artikkelen er at virkemidler presenteres $i$ en taksonomi, hvor vi ser på tiltak knyttet til utformingen av eksamen, kontroll underveis i utførelsen, og undersøkelser av besvarelser $i$ etterkant. Mange tiltak kan være effektive når det gjelder å begrense fusk ved samarbeid mellom kandidater under eksamen. Derimot fins det vesentlig færre tiltak mot fusk hvor kandidaten får hjelp av en tredjepart, selv om økt interaktivitet og muntlighet i eksamen kan bidra.
\end{abstract}

\section{INNLEDNING}

Fusk er en bekymring ved alle slags karaktergivende vurderinger (Cizek, 1999), og forskningen sier ikke entydig at hjemmeeksamen har mer fusk enn skoleeksamen (Bengtsson, 2019), men fusk blir utvilsomt lettere i fraværet av tilsyn. Holdningsskapende tiltak som æreskoder kan redusere fusk - både for skoleeksamen og hjemmeeksamen - men ikke eliminere det (Gurung et al., 2012; Tatum \& Schwarz, 2017). Plagiatsjekk kan være delvis effektivt for besvarelser som forventes å ha et sterkt individuelt preg, men i mindre grad for eksamensoppgaver med én eller noen få riktige løsninger, som ofte forekommer i grunnleggende MNT-fag. Erfaringer fra Covid-våren 2020 tyder på et stort omfang av fusk, og tilsvarende ble observert i andre land, f.eks. (Clark et al., 2020; Bilen \& Matros, 2020).

Forskningsspørsmålene for denne artikkelen er som følger:

1. Hvilke virkemidler fins for å redusere fusk ved hjemmeeksamen, utover æreskoder og plagiatsjekk?

2. Hva er fordeler og ulemper med disse virkemidlene?

Forskningsspørsmålene besvares ved gjennomgang av en del relevant litteratur om fusk, samt definisjon av en taksonomi for måter å fuske på, og en tilsvarende taksonomi for mottiltak mot fusk. Resten av artikkelen er strukturert som følger: Seksjon 2 diskuterer ulike former for fusk, og hvordan trusselbildet er forskjellig for muntlig og skriftlig hjemmeeksamen. Seksjon 3 presenterer ulike virkemidler mot fusk og diskuterer i hvilken grad de er egnet til å redusere risikoen for fusk.

\section{FORMER FOR FUSK OG MOTTILTAK}

Vi begrenser oss i denne artikkelen til å se på fusk begått av studenter, ikke av faglærere eller andre universitetsansatte, og til fusk underveis $i$ eksamen, ikke fusk før eller etter eksamen. Det fins mange måter å fuske på (Cizek, 1999), som omfang, grad av overlegg og forsett, og hvorvidt det er til egennytte eller en vennetjeneste (f.eks. en sterk kandidat som deler svar med en svakere kandidat). For diskusjonen i denne artikkelen bruker vi en taksonomi med tre kategorier av fusk:

- Alenefusk - som kan utføres av studenter enkeltvis, uten medvirkning fra andre. Typiske eksempler er ulovlige hjelpemidler og plagiat.

- Samarbeid - mellom studenter som tar samme eksamen, alt fra symmetriske samarbeid hvor de involverte bidrar like mye, til asymmetriske hvor sterkere kandidater hjelper svakere.

- Hjelp fra tredjeperson - som enten gjør hele eksamen for studenten, eller gir hjelp underveis.

Mottiltak mot fusk kan klassifiseres etter tiltakets natur. Kulturelle / holdningsskapende tiltak: Eksempel på dette er ovennevnte æreskoder. Juridiske tiltak: Tydelige regler for hva som er fusk og ikke, samt god kommunikasjon til studentene om hva reglene er. Strenge og konsekvente straffer for de som er 
skyldige i fusk. Pedagogiske tiltak: design av undervisning i løpet av semesteret, valg av vurderingsformer, spesifikke designvalg i vurderingene. En driver for økt fusk er eksamensangst, så alle bidrag til å gi følelse av mestring underveis i semesteret og redusere eksamensangst, kan også bidra til reduksjon av fusk. Kontrolltiltak: Dette kan være kontroll av studenten underveis i eksamen, eller kontroll av levert besvarelse i etterkant, for å oppdage eventuelt fusk. Kulturelle og juridiske tiltak vil i stor grad være de samme enten eksamen er på skolen eller hjemme, vi vil derfor i det følgende konsentrere oss om kontrolltiltak, som nødvendigvis er annerledes for hjemmeeksamen der mulighetene for kontroll er mindre, og pedagogiske tiltak som eventuelt kan bidra til å bøte på mangelen på kontroll. Vi vil nå diskutere fusk og mottiltak for muntlig hjemmeeksamen (seksjon 3), deretter for skriftlig hjemmeeksamen (seksjon 4), basert på denne inndelingen.

\section{MUNTLIG HJEMMEEKSAMEN}

En spesiell utfordring for muntlig er at spørsmål kan lekke fra tidligere til senere kandidater - enten det er fysisk oppmøte eller videokonferanse. Et vanlig mottiltak mot dette er å ha en masse spørsmål som studentene trekker tilfeldig mellom, men dette kan på sin side begrense eksamens pålitelighet (Davis \& Karunathilake, 2005), og hvis antallet kandidater overstiger antall spørsmålsvarianter, kan de seneste kandidatene fortsatt få fordel. Et alternativt mottiltak er å offentliggjøre alle spørsmålene på forhånd (f.eks. 20 spørsmål, hvorav hver kandidat tilfeldig vil få 3), så ingen får fordel av lekkasjer (Akimov \& Malin, 2020).

Forøvrig har muntlig generelt lavere risiko for fusk enn skriftlig, siden kandidat observeres av eksaminatorer under hele besvarelsen (Gharibyan, 2005), men videokonferanse gir noe økt risiko versus muntlig med fysisk oppmøte på universitetet. En legitimasjon fremvist over video er vanskeligere å avsløre som falsk - helst bør eksaminator ha tilgang til kandidat-ID via intranett. Videokonferanse gir dessuten mindre kontroll over studentens umiddelbare omgivelser enn det man har ved fysisk oppmøte. Hjelpemidler kan være skjult utenfor kameravinkel, denne typen fusk hindres enklest ved å tillate hjelpemidler (Maciejewski, 2020). Verre er det om studenten har en medhjelper. Med fysisk oppmøte er dette kun mulig med trådløs kommunikasjon, f.eks. via skjult ørepropp, mens hjemme kan medhjelper befinne seg hos studenten og gi hint, kanskje ved å skrive til studentens skjerm (eller en annen skjerm, i tilfelle skjermbildet på eksamens-PC'en må deles med eksaminator).

Det er lettere for en kandidat å dra nytte av ulovlig hjelp hvis det tillates å ta lange tenkepauser, for eksempel om man får et par minutt til å kladde en disposisjon før man begynner å avgi svaret, for da kan hint skrives eller letes fram i det tidsrommet. Det er også lettere hvis svarene for det meste avgis som lange monologer fra studentens side, for da kan en medhjelper samtidig gi hint om hvordan man bør fortsette. Ett interessant virkemiddel er derfor å kjøre eksamineringen mest mulig som en dialog mellom student og eksaminatorer, med noen passasjer med hyppige replikkvekslinger og plutselige oppfølgingsspørsmål. Da vil det være mye vanskeligere for en medhjelper å produsere hint raskt nok. Slike dialoger vil også lett utvikle seg ulikt fra kandidat til kandidat, så selv om noen i utgangspunktet har fått identisk spørsmål, så vil ikke et transkript av en tidligere students besvarelse fungere særlig bra som manus.

\section{SKRIFTLIG HJEMMEEKSAMEN}

Skriftlig hjemmeeksamen har langt større utfordringer med fusk enn muntlig eksamen over videokonferanse. Kontinuerlig biometrisk autentisering, f.eks. ved ansiktsgjenkjenning og tasterytme, ville kunne sikre at det er riktig person som sitter ved tastaturet (Flior \& Kowalski, 2010). Fjerntilsyn over internett, såkalt «remote proctoring», brukes av mange universiteter rundt omkring i verden. Det er delte meninger om hvor effektive slike systemer er, og utfordringer knyttet til stress og personvern ved overvåkning i hjemmet (Langenfeld, 2020), men systemene gjør utvilsomt fusk vanskeligere ved at mistenkelig atferd som kan tyde på forsøk på kommunikasjon med medhjelpere vil flagges (Hussein et al., 2020). Slike kontrolltiltak brukes imidlertid ikke under hjemmeeksamen ved norske universiteter, som i praksis skjer helt uten tilsyn, og studenter kan dermed uhindret kommunisere med medstudenter eller tredjepersoner underveis. 


\subsection{Tiltak mot samarbeid}

Analyse av besvarelsen i etterkant for å oppdage samarbeid. Plagiatsjekk er innebygget i den norske infrastrukturen for digital eksamen. I tillegg til å avdekke kopiering fra kilder - som vil være fusk hvis det ikke er henvist til kildene - kan det også avdekke deling av tekst mellom studenter, såframt den delte teksten ikke omskrives tilstrekkelig (Foltynek et al., 2020). Et supplement til plagiatsjekk kan være skjult vannmerking av innhold, som også vil kunne avdekke deling av svar med påfølgende omskriving for å omgå plagiatsjekk. For oppgaver som ikke er essay eller programkode, men flervalg, kortsvar, diagrammer etc. vil plagiatsjekk være mindre relevant. For flervalgsoppgaver og lignende autorettede spørsmålstyper kan detektering av mistenkelig sammenfall i svarmønster mellom flere kandidater være interessant (Wesolowsky, 2000). Ulempen er at det mest mistenkelige vil være stort sammenfall av gale svar, siden to studenter som begge har svart $100 \%$ korrekt, godt kan ha gjort det på grunn av dyktighet heller enn fusk. Man vil derfor primært ta ineffektive fuskere på denne måten, mens de mest effektive fuskerne vil slippe unna.

Analyse av svarprosessen for å oppdage samarbeid - enten live eller ved at data lagres og analyseres i etterkant. Uten bruk av fjerntilsyn, har ikke norske universiteter mange virkemidler i denne kategorien. Hvis tidspunkter for studenters besvarelse av deloppgaver lagres, kan f.eks. ekstremt sammenfall i tidspunkt når spørsmål besvares være mistenkelig (Metzger \& Maudoodi, 2020), likeledes hvis en kandidats besvarelse «vokser» uforholdsmessig raskt på visse tidspunkter underveis i eksamen - f.eks. mot slutten av eksamenstiden - som kan tyde på plutselig kopiering av svar man har fått tilsendt fra andre. Standard eksamensinfrastruktur støtter ikke dette i særlig grad for hjemmeeksamen i Norge, så det vil kreve ekstrainnsats av faglærer, muligens med bruk av ekstra verktøy.

Eksamensdesign for å gjøre samarbeid mer tungvint, eller mindre relevant. Det er enkelt for kandidater å samarbeide hvis (i) alle får de samme spørsmålene, (ii) i samme rekkefølge, og (iii) spørsmålene er av en slik art at plagiatsjekk ikke egner seg, slik at det er lav risiko knyttet til deling av svar. Relatert til punkt (iii) er ett mulig tiltak dermed å endre eksamensdesign ved å ha flere essayoppgaver hvor studenter skal reflektere og diskutere med egne ord, og færre flervalgs- og kortsvaroppgaver. I mange emner vil essay alene ikke være dekkende for læringsutbyttene, og selv med essayoppgaver er ulovlig samarbeid mulig. Et annet tiltak kan være at kandidatene får spørsmålene i ulik rekkefølge, og bare ser ett spørsmål om gangen, uten mulighet til å navigere tilbake (Budhai, 2020). Dette kan imidlertid ramme urettferdig med at noen studenter får en mindre gunstig rekkefølge, og særlig studenter med lesevansker som gjerne vil foretrekke innledningsvis å hoppe over spørsmål med mye tekst, for å ta disse til slutt etter at har besvart de med lite tekst (Raje \& Stitzel, 2020). Man bør derfor være forsiktig med bruken av dette virkemidlet, særlig siden nåværende støtte i f.eks. Inspera er svært grovgranulær. Et mer potent virkemiddel er dermed relatert til punkt (i), at studentene får ulike spørsmål - som vil gjøre deling av svar irrelevant, og annet samarbeid mer tungvint. En flink student som skal hjelpe en svakere, må da gjøre ekstra oppgaver i tillegg til å løse sine egne, og svekker kanskje sin egen prestasjon. Det kan enten være helt ulike spørsmål, halvveis ulike spørsmål (f.eks. alle får samme case, men ulike spørsmål som skal besvares i tilknytning til caset; eller motsatt, alle får samme spørsmål å besvare, men relatert til ulike case), eller spørsmål laget som variasjoner over en mal (Manoharan \& Ye, 2020), f.eks. hvor tallparametre byttes ut hvis det er utregninger som skal gjøres, eller små endringer i programkode som studenter skal analysere eller fullføre.

Tidspress er noe som mange faglærere intuitivt tenker kan hindre samarbeid. Til dels kan dette funke, men det er et tveegget sverd. Hvis tidspress skal ha noen vesentlig effekt, må selv de flinkeste studentene føle presset - så de ikke har tid til å hjelpe svakere studenter. I så fall blir tidspresset enda verre for middels og svakere studenter, som må regne med å slett ikke bli ferdig med alle oppgavene. Økt eksamensangst kan være en driver for økt fusk, og rent konkret kan tidspress også gi en økt oppside (forventet karaktergevinst) for fusk. Anta at $\mathrm{S}$ er en middels god student som kan ca. $70 \%$ av stoffet, men eksamen er så omfangsrik at $\mathrm{S}$ dessuten bare blir ferdig med ca. $70 \%$ av oppgavene, og ender da med en score på bare ca. $50 \%(0,7$ x 0,7) som vil gi en temmelig dårlig karakter. Det vil her klart lønne seg for to slike studenter å alliere seg og gjøre halvparten av eksamen hver og så utveksle svar, eller også å alliere seg med en flinkere student - bare for å kunne håndtere tidspresset. 


\subsection{Tiltak mot hjelp fra tredjeperson}

De ovennevnte tiltakene mot samarbeid, som plagiatsjekk, tidspress og variasjon i oppgaver, er fullstendig nytteløse overfor hjelp fra tredjeperson, siden vedkommende ikke har sin egen eksamen å gjøre samtidig. Å sette opp eksamen slik at man bare ser ett spørsmål av gangen uten mulighet til å navigere tilbake til foregående spørsmål, kan i noen grad hemme hjelp fra utenforstående (Budhai, 2020). Hvis man kan se alle spørsmålene straks etter eksamensstart, kan kandidaten raskt gjøre seg opp en mening om hvilke spørsmål han kan klare selv, og hvilke han trenger hjelp til - og umiddelbart sende disse deloppgavene til en eller flere hjelpere (venner, familiemedlemmer, kommersielle aktører) som kan løse dem parallelt med at kandidaten jobber videre med de enklere oppgavene. Med tvungen navigasjon er man derimot nødt til å ha en medhjelper som er villig til å hjelpe med hele eksamen.

Et annet virkemiddel er å gjøre vurderingen mer omfattende. Mens det kan være fullt overkommelig å finne noen som er villig til å gjøre en 4 timers eksamen for en god venn i en nødssituasjon - eller mot betaling - er det vanskeligere eller dyrere å finne noen som er villig til å gjøre et større prosjektarbeid som tar flere ukesverk og strekker seg over måneder i kalendertid. Men hva fins av virkemidler dersom man rett og slett ønsker å ha en 4-timers eksamen slik man brukte å ha før? Det må i så fall være å bruke spørsmålstyper hvor kandidatens identitet kan fastslås fra selve det innleverte svaret. Noen mulige eksempler:

- Stilanalyse («stylometry») av essayoppgaver, hvor levert besvarelse sammenlignes stilistisk med en samling tekster som man vet er skrevet av kandidaten. Pilotstudier i utlandet har vært lovende (Ison, 2020). Dette vil kunne avdekke hjelp fra en tredjeperson som skriver en helt original besvarelse, hvor plagiatsjekk ikke vil hjelpe. Håndskriftsgjenkjenning kunne tilsvarende brukes for oppgavetyper hvor studentene skriver for hånd, for eksempel matematikk - men vil ikke avsløre tilfeller hvor en medhjelper dikterer mens kandidaten selv skriver.

- Muntlige elementer i skriftlig eksamen (García-Peñalvo et al., 2020), hvor stemmegjenkjenning kan fastslå at det er rett kandidat. Ett eksempel er at man i stedet for et essay ber studenten om å lage en lysarkpresentasjon hvor det aktuelle temaet diskuteres, spiller inn og laster opp en skjermvideo. Alternativt kan man for oppgavesjangre som flervalg, programmering o.l. i tillegg til at studenten løser oppgaven skriftlig, be om at studenten gjør lydopptak av høyttenkning mens oppgaven løses, som å forklare hvorfor man velger det svaralternativet, og at dette lastes opp som Filopplasting i en direkte påfølgende deloppgave.

Bruk av muntlige elementer vil ikke forhindre at kandidater får hjelp, men vil gjøre denne hjelpen vesentlig mindre effektiv, siden den utenforstående i så fall først må løse oppgaven, deretter trene opp kandidaten til å avlevere forklaringen på en troverdig måte. Samarbeid blir også mye vanskeligere, siden studenter som sitter i samme rom lett vil få hverandres lyd inn på opptaket, og en student vanskelig kan hjelpe en medstudent samtidig som hen holder på å spille inn sin egen skjermvideo.

\section{KONKLUSJON}

Mange tiltak kan begrense fusk ved samarbeid mellom kandidater under eksamen (Von Gruenigen et al., 2018; de Sande, 2015; Fendler \& Godbey, 2016). Derimot fins det vesentlig færre tiltak mot fusk hvor kandidaten får hjelp av en tredjepart, selv om økt interaktivitet og muntlighet i eksamen kan bidra. En fullstendig eliminasjon av fusk ved hjemmeeksamen vil ikke være mulig, iallfall ikke på kort sikt, ei heller om Norge skulle begynne å bruke teknologi for biometrisk autentisering og fjerntilsyn à la andre land, da det også fins metoder for å omgå denne typen tilsyn. Likevel bør ikke dette bety at man i størst mulig grad vender tilbake til den gamle, velkjente 4-timers skoleeksamen straks Covid-19 er over - slike eksamener er heller ikke fri for fusk (Cizek, 1999; Dawson, 2020). Man bør heller bruke erfaringene man har fått til å jobbe seg fremover mot nye vurderingsformer (Fuller et al., 2020). Noen har erfart at tiltak de har prøvd ut som følge av pandemien var såpass vellykket at de vil fortsette med det senere (Clark et al., 2020; Akimov \& Malin, 2020). Veien videre kan derfor være en større variasjon i vurderingsformer, som kombinerer arbeid på skolen og hjemme, og arbeid med og uten streng kontroll.

\section{REFERANSER}

Akimov, A., \& Malin, M. (2020). When old becomes new: a case study of oral examination as an online assessment tool. Assessment \& Evaluation in Higher Education, 1-17. 
Bilen, E., \& Matros, A. (2020). Online Cheating Amid COVID-19. Available at SSRN 3691363.

Budhai, S. S. (2020) Fourteen Simple Strategies to Reduce Cheating on Online Examinations. Faculty Focus, 11 May.

Cizek, G. J. (1999). Cheating on tests: How to do it, detect it, and prevent it. Routledge.

Clark, T. M., Callam, C. S., Paul, N. M., Stoltzfus, M. W., \& Turner, D. (2020). Testing in the Time of COVID19: A Sudden Transition to Unproctored Online Exams. Journal of Chemical Education.

Davis, M. H., \& Karunathilake, I. (2005). The place of the oral examination in today's assessment systems. Medical teacher, 27(4), 294-297.

Dawson, P. (2020). Defending assessment security in a digital world: preventing e-cheating and supporting academic integrity in higher education. Routledge.

de Sande, J. C. G. (2015). Calculated questions and e-cheating: A case study. Education Applications \& Developments Advances in Education and Educational Trends Series, 2(3), 91-99.

D'Souza, K. A., \& Siegfeldt, D. V. (2017). A Conceptual Framework for Detecting Cheating in Online and TakeHome Exams. Decision Sciences Journal of Innovative Education, 15(4), 370-391.

Fendler, R. J., \& Godbey, J. M. (2016). Cheaters should never win: Eliminating the benefits of cheating. Journal of Academic Ethics, 14(1), 71-85.

Flior, E., \& Kowalski, K. (2010, April). Continuous biometric user authentication in online examinations. In 2010 Seventh International Conference on Information Technology: New Generations (pp. 488-492). IEEE.

Foltýnek, T., et al. (2020). Testing of support tools for plagiarism detection. International Journal of Educational Technology in Higher Education, 17(1).

Fuller, R., Joynes, V., Cooper, J., Boursicot, K., \& Roberts, T. (2020). Could COVID-19 be our 'There is no alternative'(TINA) opportunity to enhance assessment?. Medical teacher, 42(7), 781-786.

García-Peñalvo, F. J., Corell, A., Abella-García, V., \& Grande-de-Prado, M. (2020). Recommendations for Mandatory Online Assessment in Higher Education During the COVID-19 Pandemic. In Radical Solutions for Education in a Crisis Context (pp. 85-98). Springer, Singapore.

Gharibyan, H. (2005). Assessing students' knowledge: oral exams vs. written tests. ACM SIGCSE Bulletin, 37(3), 143-147.

Giordano, A. N., \& Christopher, C. R. (2020). Repurposing Best Teaching Practices for Remote Learning Environments: Chemistry in the News and Oral Examinations During COVID-19. Journal of Chemical Education, 97(9), 2815-2818.

Gurung, R. A., Wilhelm, T. M., \& Filz, T. (2012). Optimizing honor codes for online exam administration. Ethics \& Behavior, 22(2), 158-162.

Hussein, M. J., Yusuf, J., Deb, A. S., Fong, L., \& Naidu, S. (2020). An Evaluation of Online Proctoring Tools. Open Praxis, 12(4), 509-525.

Ison, D. C. (2020). Detection of Online Contract Cheating through Stylometry: A Pilot Study. Online Learning, 24(2), 142-165.

Langenfeld, T. (2020). Internet-Based Proctored Assessment: Security and Fairness Issues. Educational Measurement: Issues and Practice, 39(3), 24-27.

Maciejewski, W. (2020). Let Your Students Cheat on Exams. PRIMUS, 1-14.

Manoharan, S., \& Ye, X. (2020, November). On Upholding Academic Integrity in Online Examinations. In 2020 IEEE Conference on e-Learning, e-Management and e-Services (IC3e) (pp. 33-37). IEEE.

McCabe, D. L., Butterfield, K. D., \& Trevino, L. K. (2012). Cheating in college: Why students do it and what educators can do about it. JHU Press.

Metzger, R., \& Maudoodi, R. (2020, April). Using Access Reports and API Logs as Additional Tools to Identify Exam Cheating. In Society for Information Technology \& Teacher Education International Conference (pp. 294-299). Association for the Advancement of Computing in Education (AACE).

Raje, S., \& Stitzel, S. (2020). Strategies for effective assessments while ensuring academic integrity in general chemistry courses during COVID-19. Journal of Chemical Education, 97(9), 3436-3440.

Tatum, H., \& Schwartz, B. M. (2017). Honor codes: Evidence based strategies for improving academic integrity. Theory Into Practice, 56(2), 129-135.

Von Gruenigen, D., de Souza, F. B. D. A., Pradarelli, B., Magid, A., \& Cieliebak, M. (2018, April). Best practices in e-assessments with a special focus on cheating prevention. In 2018 IEEE Global Engineering Education Conference (EDUCON) (pp. 893-899). IEEE.

Wesolowsky, G. O. (2000). Detecting excessive similarity in answers on multiple choice exams. Journal of Applied Statistics, 27(7), 909-921. 